\title{
VERIFICATION OF TACTICAL AND TECHNICAL DATA OF THE BREATHING APPARATUS
}

\author{
Tatiana Verešová ${ }^{1}$, Jozef Svetlík ${ }^{2}$, Dávid Kalužník ${ }^{3}$
}

\begin{abstract}
The function of the breathing apparatus is to protect the health of firefighters in a harmful and non-respirable environment. Closed-circuit breathing apparatus provides members of the Fire and Rescue Service with respiratory protection in the elimination of adverse events in tunnels and underground spaces. The MSA 4h Air Elite is a four-hour self-contained breathing apparatus that operates on the principle of generating oxygen by an exothermic reaction of potassium hyperoxide. Each breathing apparatus has its tactical technical parameters. We verified the tactical and technical data of the MSA AIRE ELITE by the experiment they participated in the firefighter. Each firefighter was equally coupled. An MSA Air Elite was used during the experiment. Tactical-technical data reported by the manufacturer varies in some points with the practical results that we have managed to obtain. The manufacturer's largest deviations in tactical and technical data and practical results are mainly in the length of work activity, temperature in use in intervention, and air consumption. According to our experiment, the MSA 4h Air Elite breathing apparatus does not last in the working activity 240 minutes as it discloses a manufacturer, but on the other hand, this time-inconsistency may be caused by the intensity of training and demanding of the training track.
\end{abstract}

UDC Classification: 351, DOI: https://doi.org/10.12955/pns.v2.160

Keywords: breathing apparatus, closed-circuit, firefighting

\section{Introduction}

Breathing apparatus is currently a necessary element in the work of firefighters. They are constantly being improved, and their tactical and technical parameters are identified in more detail, for the individual environments in which they are to be used, or for the conditions in which they should be able to carry out their activities. In many cases, a situation arises where the information provided by the manufacturer on his products does not meet the criteria. The aim of the test and the article is to verify and determine the limited possibilities of the used equipment for the needs of a specific fire brigade..

\section{Breathing apparatus}

The breathing apparatus is intended for the protection of the respiratory tract of persons working in a non-respirable and harmful environment. Breathing apparatus used in firefighting units are usually autonomous open-circuit breathing apparatus. They consist of a pressure vessel, carrier, shoulder straps, hip straps, pressure reducing valve, rubber hose, manometer and lung automation (Monoši, 2016). The breathing apparatus divided into isolation and filtration.

\section{Self-contained breathing apparatus MSA 4 H air elite}

MSA Air Elite 4h (Figure 1) with a slim construction and ergonomic design provides maximum comfort, with the center of gravity located at the waist and without protruding shoulder width. The side breathing tubes are close to the body for easy putting on and taking off even in confined spaces, without removing the mask. It provides excellent breathing comfort thanks to low breathing resistance, low inhalation temperature and dry breathing air. It has maintenance-free standby storage for up to 2 years and is in full standby mode for up to 8 years if the canisters are in a sealed state (MSA AUER, 2020).

The device contains two canisters with chemicals that are connected in parallel. They contain potassium hyperoxide, which is necessary for the regeneration of the respiratory medium. The canisters are equipped with quick starters and are stored in cooling jackets. Chemical tanks can only be used once and must be replaced after use (The Safety Company, 2020).

The main tactical and technical data of MSA Air Elite are shown in Table 1.

\section{Verification of tactical and technical parameters of MSA 4H air elite}

Verification of the tactical and technical parameters of the MSA 4h Air Elite breathing apparatus was performed at the fire station in Žilina of the District Directorate of the Fire brigade in Žilina. To verify the tactical and technical parameters, we performed a training exercise with members of the Fire brigade. During training with breathing apparatus, members of the Fire brigade were equipped with personal protective equipment to maintain safety at work.

\footnotetext{
${ }^{1}$ University of Žilina, Faculty of Safety ingineering, Žilina, Slovakia, Tatiana.veresova@fbi.uniza.sk

${ }^{2}$ University of Žilina, Faculty of Safety ingineering, Žilina, Slovakia, jozef.svetlik@fbi.uniza.sk

${ }^{3}$ University of Žilina, Faculty of Safety ingineering, Fire Brigade of Žilina, Žilina, Slovakia, kaluznik2@stud.uniza.sk,
} 


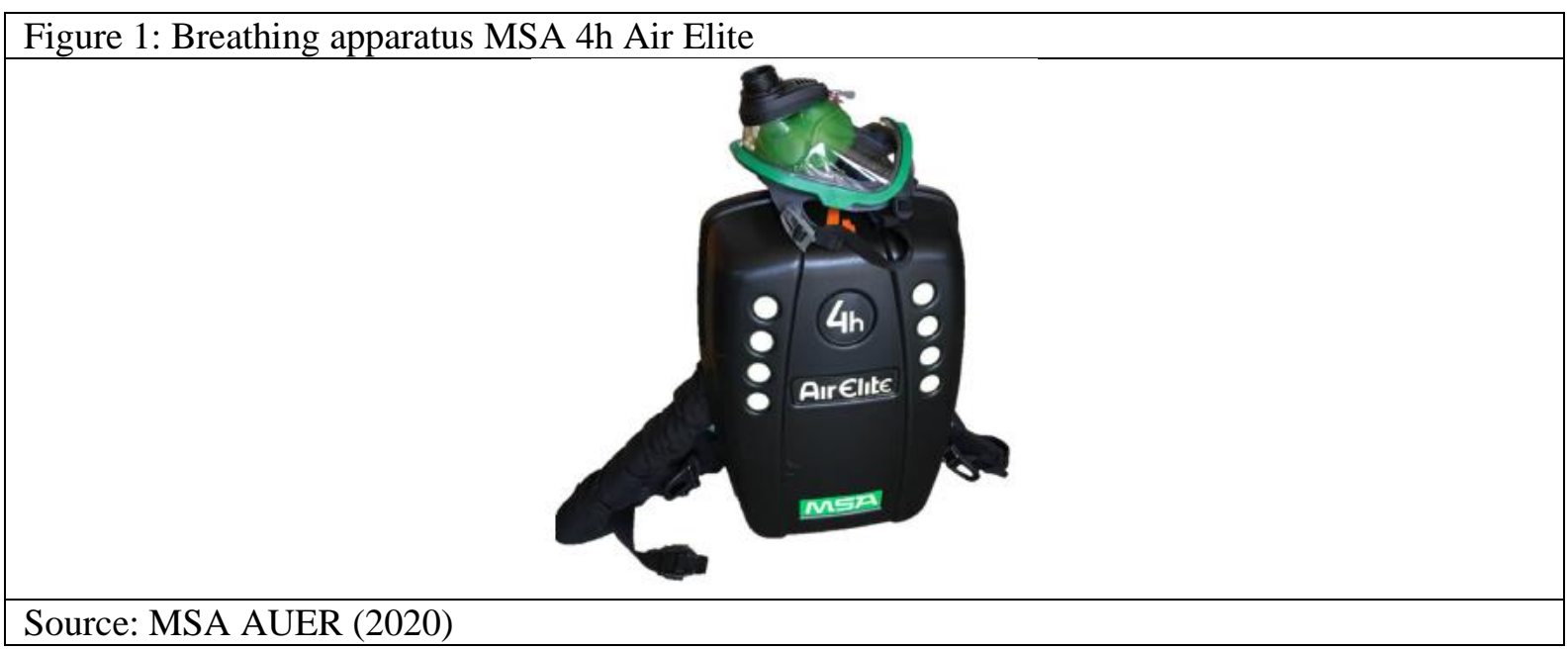

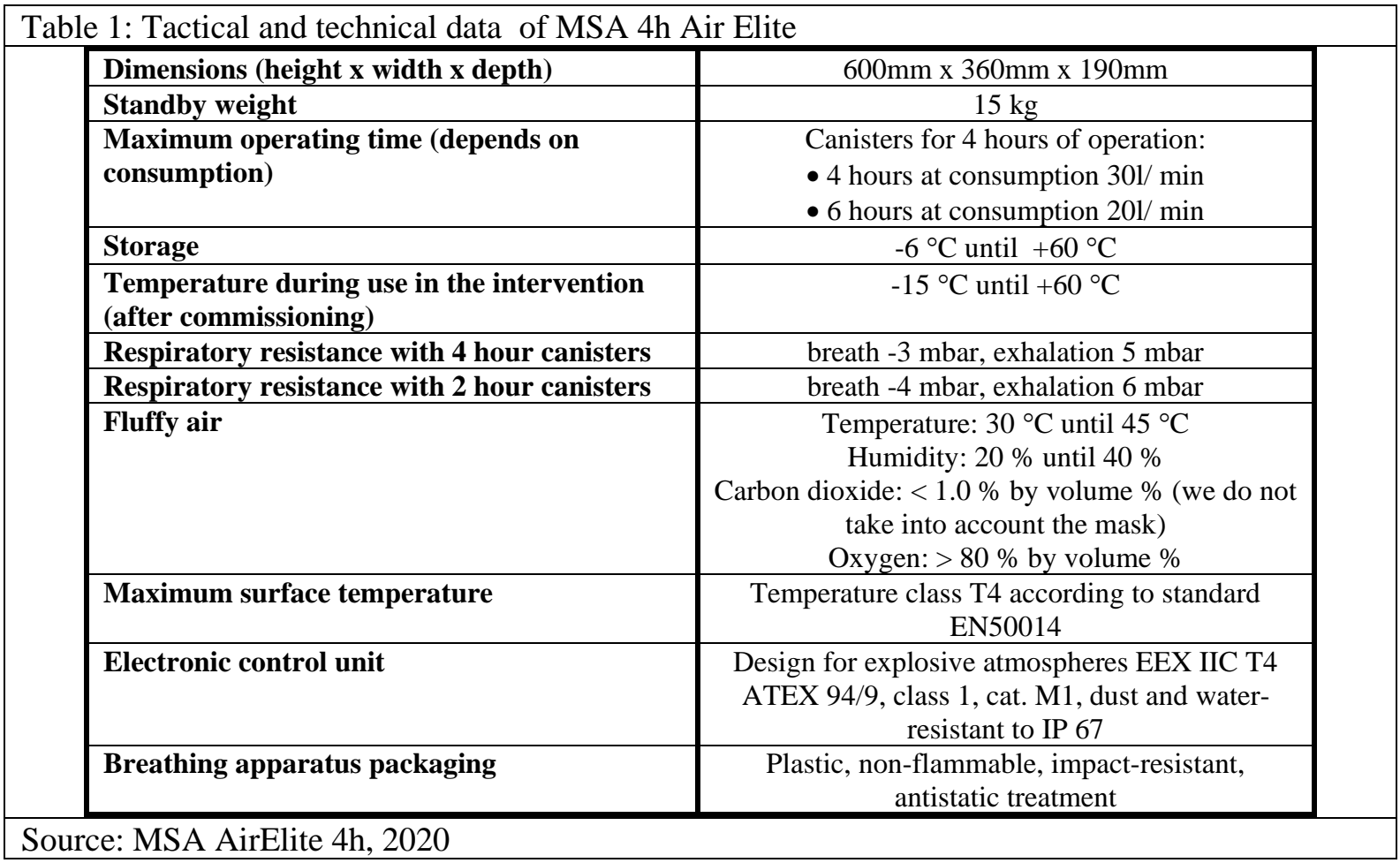

Each Fire brigade member who participated in training with the MSA 4h Air Elite breathing apparatus had personal equipment consisting of a full-face MSA Advantage 4000 AirElite mask, IC-Air control monitor, shoulder straps, hip straps, emergency gloves, MSA Gallet F1SF emergency helmet, connection of the inhalation and exhalation hose to the mask, inhalation and exhalation hose in a heatresistant packaging, work shoes, self-contained breathing apparatus with a closed-circuit MSA 4h Air Elite, work uniforms of a Fire brigade member and station clothing.

The training track consisted of four obstacles. The first obstacle section was the section with the transfer of hose baskets ( $2 \mathrm{x}$ hose baskets consisting of 4 hoses $\mathrm{C} 52 \mathrm{~mm}$ transferred in the hands to a distance of $40 \mathrm{~m}$ ). The second section consisted of leaning the retractable ladder against the training tower (twopart retractable ladder, length of the retracted ladder $9 \mathrm{~m}$ ) and then ascending to the 4th floor of the training tower by stairs. The last section consisted of transferring the manikin in any way to a distance of $40 \mathrm{~m}$, while the weight of the manikin was $50 \mathrm{~kg}$.

\section{Training results}

The training verified the tactical parameters of the MSA 4h Air Elite closed-circuit breathing apparatus. These parameters are important for the operation of the fire brigade at the scene of an emergency. One breathing apparatus used by five Fire brigade trainers was used for the training. 


\section{Measured tactical and technical parameters:}

1. Maximum operating time - this is the time during which the breathing apparatus will produce oxygen. During this time, members of the Fire brigade may be deployed in the intervention.

2. Respiratory resistance - depends on the magnitude of the resistance, how easy or difficult it is for the affected person to breathe when using the device. Respiratory resistance could not be measured during training.

3. Battery life - The battery is powered by an IC-Air control monitor and a fan that cools the inhaled air. The battery lasted during the entire training period.

From the point of view of intervention activity, the most important tactical parameter is air consumption, ie how long the breathing apparatus can produce oxygen. The measured values during training are shown in Table 2.

\begin{tabular}{|l|c|c|c|c|c|c|}
\hline \multicolumn{2}{|c|}{ Table 2: Measured values during training of fire brigade's members } \\
\hline \multirow{2}{*}{} & \multicolumn{2}{c|}{$\begin{array}{c}\text { air temperature } \\
\text { training time }\end{array}$} & \multicolumn{2}{c|}{$\begin{array}{c}\text { condition of breathing } \\
\text { apparatus operation }\end{array}$} \\
\cline { 2 - 7 } & start [min] & finish [min] & start [ $\mathrm{C}]$ & finish [ $\left.{ }^{\circ} \mathrm{C}\right]$ & start [\%] & finish [\%] \\
\hline Firefighter 1 & 0 & 25 & 25.2 & 34.0 & 100 & 87 \\
\hline Firefighter 2 & 30 & 55 & 34.0 & 36.2 & 85 & 68 \\
\hline Firefighter 3 & 60 & 85 & 35.9 & 36.4 & 66 & 53 \\
\hline Firefighter 4 & 90 & 115 & 34.0 & 36.8 & 50 & 38 \\
\hline Firefighter 5 & 120 & 145 & 35.2 & 36.5 & 36 & 24 \\
\hline Source: Author
\end{tabular}

The comparison of tactical and technical parameters of MSA 4h Air Elite is shown in Table 3, in which the parameters given by the manufacturer and the parameters measured by us are given.

\begin{tabular}{|c|c|c|}
\hline & Parametre udané výrobcom & Namerané parametre \\
\hline $\begin{array}{l}\text { Dimensions (height } \mathrm{x} \text { width } \mathrm{x} \\
\text { depth) }\end{array}$ & $600 \mathrm{~mm} \times 360 \mathrm{~mm} \times 190 \mathrm{~mm}$ & $\begin{array}{c}600 \mathrm{~mm} \times 360 \mathrm{~mm} \times \\
190 \mathrm{~mm}\end{array}$ \\
\hline Standby weight & $15 \mathrm{~kg}$ & $15 \mathrm{~kg}$ \\
\hline $\begin{array}{l}\text { Maximum operating time } \\
\text { (depends on consumption) }\end{array}$ & $\begin{array}{l}\text { Canisters for } 4 \text { hours of operation: } \\
\text { - } 4 \text { hours at consumption } 301 / \mathrm{min} \\
\text { - } 6 \text { hours at consumption } 201 / \mathrm{min}\end{array}$ & $\begin{array}{l}\text { Canisters for } 4 \text { hours of } \\
\text { operation: } \\
3 \text { hours at } \\
\text { consumption } \\
401 / \mathrm{min}\end{array}$ \\
\hline Storage & $-6^{\circ} \mathrm{C}$ until $+60^{\circ} \mathrm{C}$ & $21^{\circ} \mathrm{C}$ \\
\hline $\begin{array}{l}\text { Temperature during use in the } \\
\text { intervention (after commissioning) }\end{array}$ & $-15^{\circ} \mathrm{C}$ until $+60^{\circ} \mathrm{C}$ & $23^{\circ} \mathrm{C}$ \\
\hline Fluffy air & $\begin{array}{c}\text { Temperature: } 30{ }^{\circ} \mathrm{C} \text { until } 45^{\circ} \mathrm{C} \\
\text { Humidity: } 20 \% \text { until } 40 \% \\
\text { Carbon dioxide: }<1.0 \% \text { by volume } \\
\% \text { (we do not take into account the } \\
\text { mask) } \\
\text { Oxygen: }>80 \% \text { by volume } \%\end{array}$ & $36.8^{\circ} \mathrm{C}$ \\
\hline Maximum surface temperature & $\begin{array}{c}\text { Temperature class T4 according to } \\
\text { standard EN50014 }\end{array}$ & $43^{\circ} \mathrm{C}$ \\
\hline
\end{tabular}

\section{Maximum operating time}

The maximum operating time is specified by the manufacturer for four hours at a consumption of 30 1/min. From Table 2 we find that one breathing apparatus can withstand the operation of five members. When the respirator is at 50\%, an audible signal sounds on the IC-Air. It is a signal for an intervening firefighter to begin to retreat from an infested or non-breathable environment. In this case, a warning signal sounded for 90 minutes, which means that the breathing apparatus will last at a consumption of $401 /$ min - 180 minutes. The members had a consumption of more than $301 /$ min. The breathing apparatus will not last 240 minutes in this case. This fact can be caused by the complexity of the training path and the high intensity of training. The time of the respirator exchange between members should be 
taken into account, which would probably only happen once, or not once, in the event of a sharp intervention - the member would exhale the entire respirator once. In all rotations, a total of $9 \%$ of the total capacity of the MSA 4h Air Elite breathing apparatus was spent.

The manufacturer states that the MSA 4h Air Elite breathing apparatus lasts for four hours at a $301 /$ min consumption. From the values given in Table 2, we find that the consumption of members was $401 /$ min. This fact can be caused by the complexity of the training path. We can assume that the consumption would be even higher because the interventions are performed by members in emergency clothing, which significantly contributes to the overheating of the body. This phenomenon would also cause more frequent breaks in dealing with the consequences of an emergency situation in an infected area.

\section{Inhaled air temperature when used in intervention}

The value of the final measured temperature after each member of the Rescue and Fire Brigade depends on his consumption, the faster the member of the fire brigade breathes, the faster the exothermic reaction in canisters with $\mathrm{KO} 2$, and the cooler does not manage to cool the air in the breathing apparatus circuit enough.

It can be seen in Figure 2 that the measured temperature of the inhaled air at the end of the training is higher than the initial temperature immediately after starting the breathing apparatus. This phenomenon can be explained by the presence of an ongoing exothermic reaction in the canisters of a respirator. An exothermic reaction may occur while using the respirator at temperatures up to $100{ }^{\circ} \mathrm{C}$.

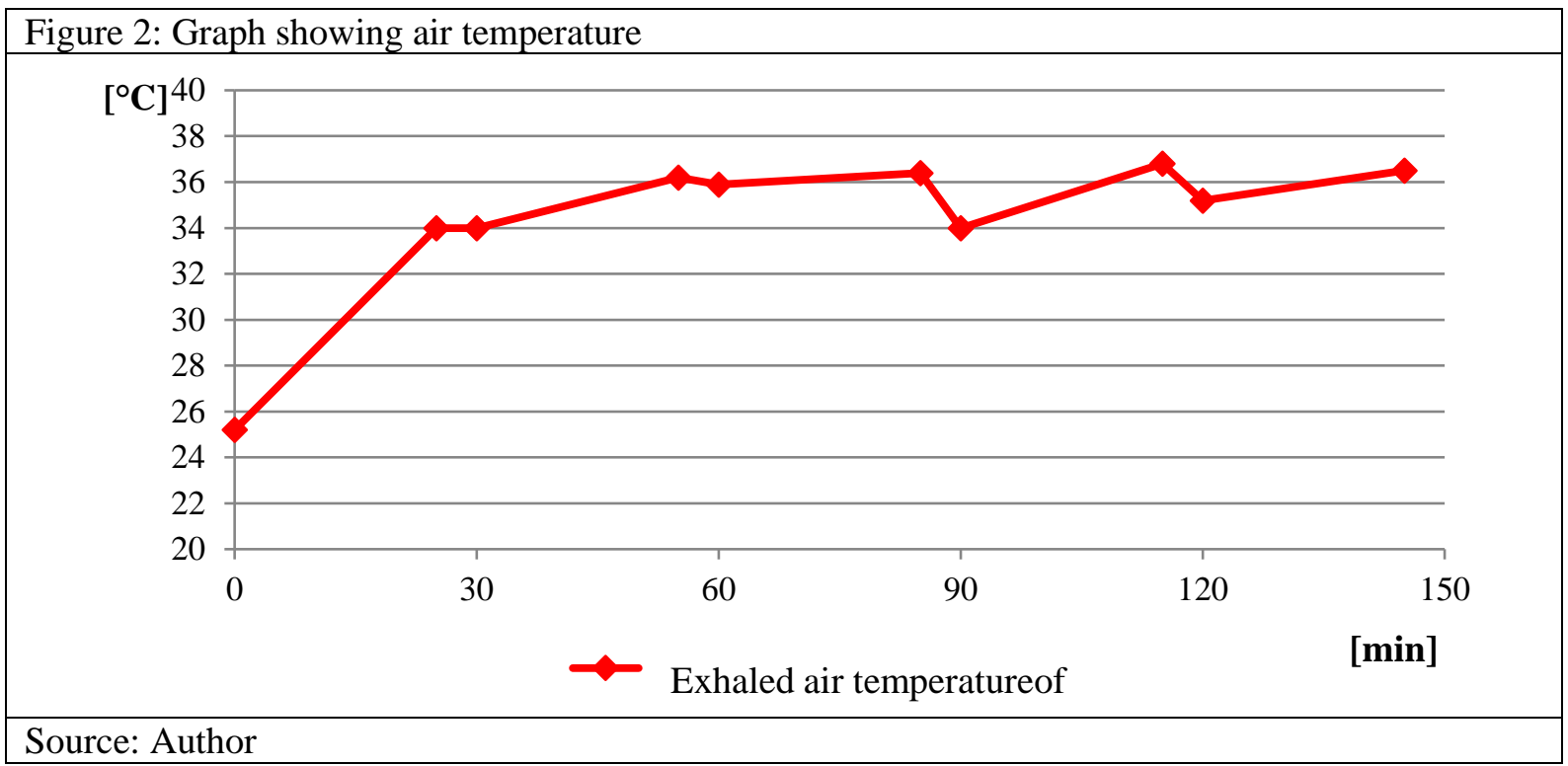

In Figure 2 we can see that the breathing apparatus, during its operation, still cools the air in its circuit. The air is cooled by a fan in the MSA 4h Air Elite breathing apparatus. During the exchange between the members, the temperature dropped, which is shown in the graph as a decreasing curve. The exchange occurred at the point when the curve took a downward trend. At the time of replacement of the breathing apparatus from member 1 to member 2 between 0.25 and 0.30 , the breathing apparatus did not cool down and remained at a temperature of $34.0^{\circ} \mathrm{C}$. With the next rotation of members by 0.55 to 1.00 , the temperature dropped from $36.2{ }^{\circ} \mathrm{C}$ to $35.9{ }^{\circ} \mathrm{C}$. The highest measured temperature was $36.8{ }^{\circ} \mathrm{C}$. This temperature is also the last measured. Because the training was terminated. The magnitude of the measured temperature is related to the intensity of breathing and thus directly proportional to the air consumption.

The air consumption directly depends on the member's physical condition and on the intensity and complexity of the activity performed in eliminating the consequences of an emergency. The training air consumption is shown in Figure 3. Oxygen is chemically generated in the MSA 4h AirElite breathing apparatus. Therefore, the IC-Air control monitor shows the remaining percentage of air that the canisters can generate.

At the end of the training, the cover of the MSA 4H Air Elite breathing apparatus was removed. The temperature of the canisters was $74^{\circ} \mathrm{C}$ after the end of the training. 


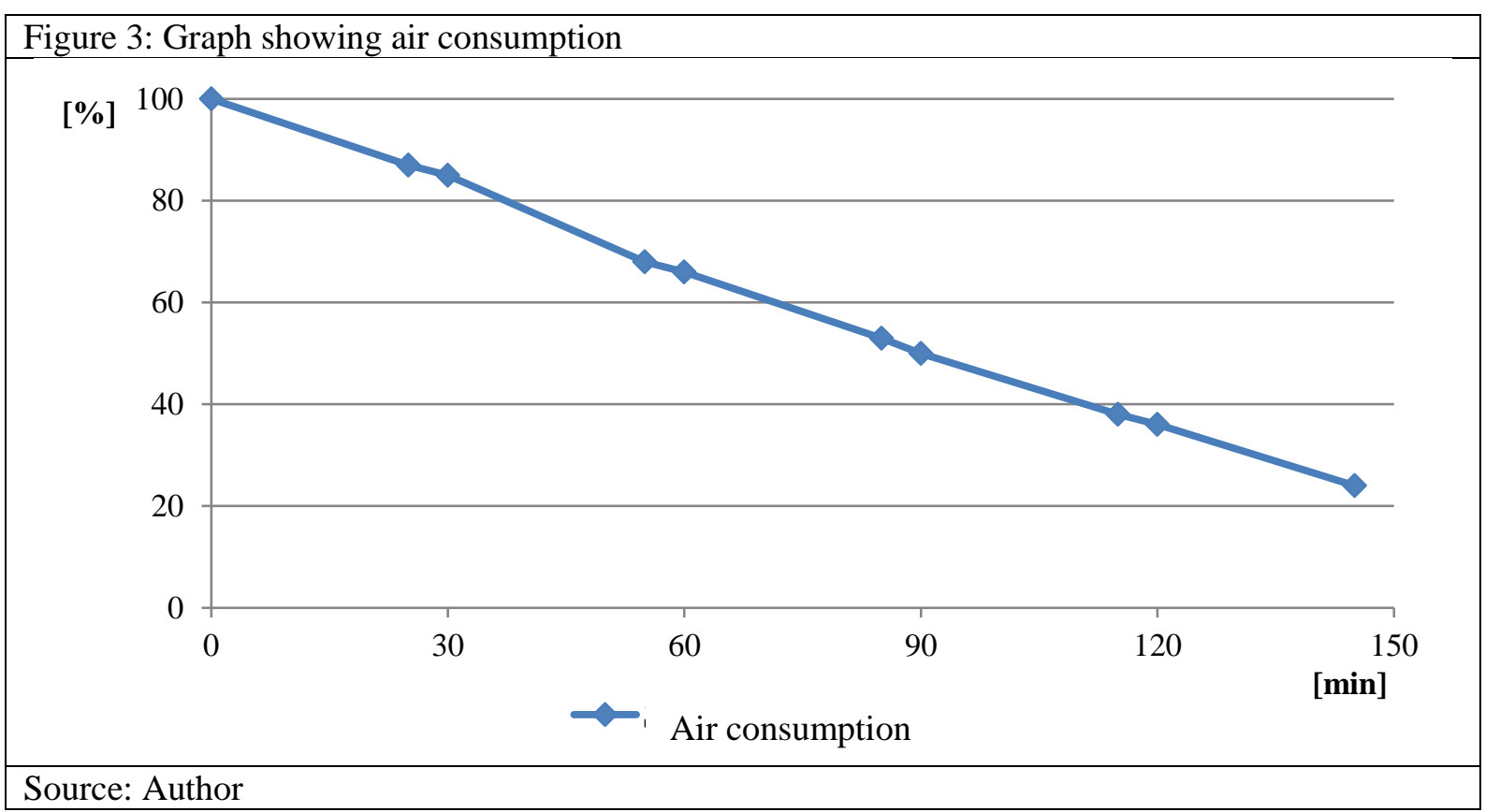

\section{Conclusion}

Breathing apparatus is an essential means of carrying out the work of firefighters in a harmful and nonrespirable environment, as they protect their health and help them function and operate in conditions in which they would not be able to perform without the aids. There are a number of breathing apparatus on the market, which differ in their tactical and technical parameters and design. The MSA 4H Air Elite breathing apparatus is a breathing apparatus with a lifespan of up to 4 hours during work. The tactical and technical data provided by the manufacturer do not correspond in some points to the practical results we managed to obtain. According to our experiment, the MSA 4h Air Elite breathing apparatus does not last 240 minutes in operation, as stated by the manufacturer, but on the other hand, this time discrepancy can be caused by the intensity of training and the complexity of the training path. Technical parameter - the temperature when used in the intervention depends on the air consumption because the faster the Fire and Rescue Brigade member breathes, the higher the temperature increases. Air consumption is affected by the condition of the user of the MSA 4h Air Elite breathing apparatus.

\section{Conflict of interest}

The authors: Tatiana Verešová, Jozef Svetlík and Dávid Kalužník certify that they have NO affiliations with or involvement in any organization or entity with any financial interest (such as honoraria; educational grants; participation in speakers' bureaus; membership, employment, consultancies, stock ownership, or other equity interest; and expert testimony or patent-licensing arrangements), or nonfinancial interest (such as personal or professional relationships, affiliations, knowledge or beliefs) in the subject matter or materials discussed in this manuscript.

\section{References}

Monoši, M., Dermek, M., Ballay, M.,(2016). Technique and technical means of fire brigades. University of Zilina: Žilina. Slovakia

Msa auer (2020). MSA AUER GmbH. Retrieved from: https://pl.msasafety.com/Supplied-Air-Respirators$\% 28$ SCBA\%29/Self-Contained-Closed-Circuit-Breathing-Apparatus/AirElite-4h---Closed-Circuit-BreathingApparatus/p/000010000300001102

MSA AirElite 4h Breathing Apparatus (2020). MSA AUER GmbH. Retrieved from: http://s7d9.scene7.com/is/content/minesafetyappliances/Manual\%20AirElite\%204H\%20-\%20GB 